\title{
Numerical Investigation of the Free and Ducted Fuel Injections under Compression Ignition Conditions
}

\author{
Xinlei Liu,* Balaji Mohan, and Hong G. Im \\ Cite This: https://dx.doi.org/10.1021/acs.energyfuels.0c02757 \\ Read Online
}

ABSTRACT: A ducted fuel injection (DFI) strategy has been proposed as an efficient approach to reduce the soot emission in direct-injection compression ignition engines. By injecting the fuel through a small tube within the combustion chamber, a leaner air-fuel mixture is generated compared to the conventional free spray approach, which significantly inhibits the soot formation and helps to reduce the dependence of the engine on after-treatment systems. However, the soot reduction mechanism is still not fully understood. Therefore, in this work, a three-dimensional computational investigation was performed to explain the experimental results. Four different reduced chemical mechanisms were used to simulate the reacting spray A ( $n$-dodecane) data from both the Engine Combustion Network group and literature. An improved post-processing method was also proposed to investigate the detailed combustion feature. The results revealed that the ignition processes using different mechanisms were all dominated by the same reaction $\mathrm{CH}_{2} \mathrm{O}+\mathrm{OH}=\mathrm{HCO}+\mathrm{H}_{2} \mathrm{O}$. Of the four reduced mechanisms, Yao mech demonstrated the best-predicted performance. Compared to the free-spray case, the DFI case generated a longer ignition delay and lift-off length and lower soot concentration owing to the significant reduction of air entrainment and longer core jet velocity from the duct exit to the lift-off length location. In addition, the DFI case had a significantly longer low-temperature heat release region but a shorter hightemperature heat release region and a smaller core between these two regions, which helps to reduce the sooting tendency.

\section{INTRODUCTION}

Internal combustion engines (ICEs) will remain a major part of the transportation sector in the next decades. ${ }^{1,2}$ To meet the more and more stringent emission regulations, further improvements in ICEs with more advanced combustion technologies need to be implemented. ${ }^{3}$ Compared to the spark-ignited (SI) engines, the compression ignition (CI) engines typically have higher thermal efficiency due to a higher compression ratio. Therefore, for the high-load facilities like ships and trucks, CI engines are frequently adopted. For the SI engines, emissions can be reduced tremendously by using only a three-way catalyst. However, for the CI engines, the reduction of harmful emissions is still challenging and mainly relies on the optimization of the combustion process, considering the high cost of the after-treatment system.

Soot emission is a major issue for diesel CI engines. ${ }^{4}$ Owing to the diffusion combustion process, the rich air-fuel mixture leads to a high level of soot precursors, promoting the particulate formation significantly. ${ }^{5}$ Improving the air-fuel mixing process is the most effective method to reduce soot emissions, which inhibits the formation of locally over-rich regions and enhances the soot oxidation process. ${ }^{6}$ The recent development of advanced fuel injection technology allows precise control of multiple injections at high-pressure conditions. When combined with the supercharging technique, soot emission can be reduced tremendously even under the high-load conditions. ${ }^{7}$

Nitric oxide (NOx) emission is another challenge for diesel engines, which is primarily formed in the locally hightemperature and oxygen-rich regions. ${ }^{8}$ To eliminate $\mathrm{NO} x$ emissions, researchers proposed the low-temperature combustion (LTC) strategy by using the exhaust gas recirculation (EGR) approach. ${ }^{9}$ However, with the increase of the EGR rate, there is a trade-off relationship between the $\mathrm{NO} x$ and soot emissions, making it difficult to eliminate them both simultaneously. ${ }^{4}$ As a result, to meet the emission regulation, a combination of the diesel particulate filter (DPF) system and the selective catalytic reduction (SCR) system needs to be installed, which increases the engine cost and impairs the engine performance. ${ }^{10-12}$

Recently, Mueller and coworkers ${ }^{10,13-15}$ first proposed a novel ducted fuel injection (DFI) method, which can reduce soot emissions for the direct-injection heavy-duty diesel engines even under a high EGR condition. By injecting a fuel through a small duct mounted downstream of the nozzle tip within the combustion chamber, the air-fuel mixing condition in the auto-ignition zone was changed, and soot formation was significantly inhibited. ${ }^{13,14}$ Their more recent experimental work on a single-cylinder optical engine demonstrated that the DFI strategy generated a longer ignition delay compared to the free injection strategy, which enhanced the air-fuel mixing process and reduced the soot emission significantly. In addition, the DFI strategy was able to maintain

Received: August 15, 2020

Revised: September 25, 2020 
a comparable engine combustion performance compared to the conventional free spray method. ${ }^{10}$

Fitzgerald et al. ${ }^{15,16}$ investigated the effects of different duct diameters and standoff distances on the soot formation of a single diesel jet. They reported that soot luminosity could be reduced by about 50\% under CI engine combustion conditions. More recently, Li et al. ${ }^{17-19}$ measured the diesel spray penetrations for the DFI and free spray methods under non-evaporating conditions. They reported that the DFI method generated a significantly longer spray penetration compared to the free spray method, especially with high injection pressures.

Although the DFI strategy has the potential to avoid the trade-off relationship between soot and NOx emissions, there are still many challenges to be resolved before implementation for practical engines. In particular, a detailed understanding of the underlying mechanism of soot reduction by using the DFI method is needed. However, up until now, there are still few numerical works related to this topic. Fitzgerald ${ }^{16}$ has numerically studied the DFI and free spray methods fueled with diesel, but they adopted $n$-dodecane to represent the chemical kinetics of diesel, which contains lots of aromatics. To better capture the experimental result, it is necessary to select a robust combustion mechanism to represent fuel chemistry. Furthermore, there is a need to compare the different spray-flame structures for the DFI and free spray methods, which helps to understand the impact of DFI on the soot reduction mechanism. To achieve this, a post-processing tool to analyze the heat release feature is needed. ${ }^{20,21}$

This work focuses on studying the chemical and physical factors that can potentially affect the combustion process for the DFI strategy. The experimental data related to spray A ( $n$ dodecane) from the Engine Combustion Network (ECN) ${ }^{22}$ and literature ${ }^{14}$ are adopted for numerical validations The effects of four different reduced $n$-dodecane mechanisms on the flame structure of spray A ( $n$-dodecane) are studied. By comparing the free injection and DFI simulation cases, the impact of the duct on the spray-flame structure and the enabling mechanism of soot reduction for the DFI method are elucidated.

\section{EXPERIMENTAL DATA}

Experimental data from the ECN website (non-reacting and reacting free sprays) ${ }^{22}$ and Gehmlich et al.'s work (reacting free and ducted sprays $)^{14}$ were adopted for numerical validations. The experiments were fueled with $n$-dodecane and performed in a constant volume chamber (CVC), which has a cubical-shaped geometry with a dimension of $108 \times 108 \times 108 \mathrm{~mm}$. Table 1 summarizes the major experimental parameters. For both the non-reacting and reacting cases, the injection pressure was kept at about 1500 bar. For the nonreacting case, liquid and vapor penetration length data were collected

\section{Table 1. Experimental Conditions}

\begin{tabular}{|lcl|}
\multicolumn{1}{c}{ parameters } & evaporation & reacting \\
\hline ambient temperature $(\mathrm{K})$ & 900 & $850-1200$ \\
ambient density $\left(\mathrm{kg} / \mathrm{m}^{3}\right)$ & 22.8 & 23.8 \\
injector diameter $(\mathrm{mm})$ & 0.09 & 0.09 \\
injection pressure $(\mathrm{MPa})$ & 150 & 150 \\
injection mass $(\mathrm{mg})$ & 3.5 & 10.7 \\
injection duration $(\mathrm{ms})$ & 1.5 & 4.0 \\
fuel temperature $(\mathrm{K})$ & 373 & 363 \\
ambient oxygen content $(\mathrm{vol} \%)$ & 0.0 & $15.0,21.0$
\end{tabular}

for calibration of the spray models. For the reacting cases, two different sets of data with ambient oxygen contents of 21 and $15 \%$ (volume fraction) were collected. In addition, measured ignition delays, lift-off lengths, and soot distributions were utilized to further validate the combustion models.

Figure 1 depicts the duct geometry adopted in this work. This duct is laid $1.4 \mathrm{~mm}$ downstream of the nozzle tip and has a length of 16
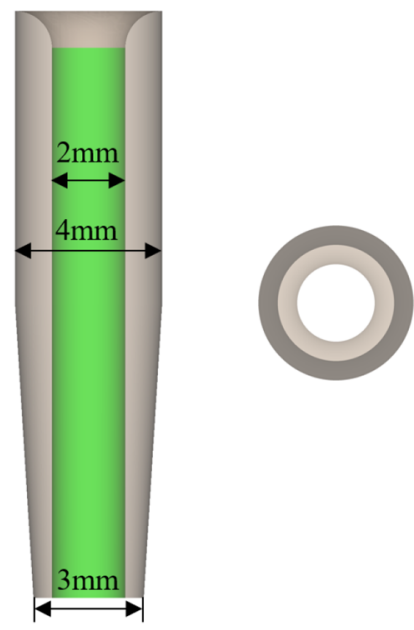

\section{Side view Top view}

Figure 1. Side and top views of the duct geometry.

$\mathrm{mm}$, an inner diameter of $2 \mathrm{~mm}$, and upper and lower wall thicknesses of 1 and $0.5 \mathrm{~mm}$, respectively. Note that there is a chamfer with a radius of $0.5 \mathrm{~mm}$ at the entrance and taper at the exit. Compared to the other three different types of ducts, the $\delta$-type ones exhibited the highest soot reduction capability. ${ }^{14}$

\section{COMPUTATIONAL SETUP}

3.1. Computational Models. The three-dimensional (3D) computational fluid dynamics (CFD) software CONVERGE (version 3.0) was used for the modeling study. The renormalization group ( $\mathrm{RNG}$ ) $\mathrm{k}-\varepsilon$ model was used to simulate turbulence. The Lagrangian-parcel Eulerian-fluid method was used to simulate the spray process. ${ }^{23}$ The Kelvin-Helmholtz Rayleigh-Taylor model without a breakup length was used to simulate the spray-breakup process. ${ }^{24}$ The no time counter algorithm $^{25}$ was used to simulate droplet collisions. The Frössling correlation was used to simulate droplet evaporation. ${ }^{26}$ The wall film model was used to simulate spray-wall interaction. The heat transfer process was simulated by using the model developed by Amsden. ${ }^{27}$ For combustion modeling, a detailed chemistry solver (SAGE) ${ }^{28}$ coupled with detailed chemical kinetics mechanisms was adopted. Figure 2 shows the rate of injection (ROI) profile adopted for simulations of this work, which was calculated with the recommended code from the ECN website.

Four different reduced $n$-dodecane mechanisms developed by Luo et al. (Luo mech), ${ }^{29}$ Yao et al. (Yao mech), ${ }^{30}$ Cai et al. (Cai mech), ${ }^{31}$ and Ren et al. (Ren mech) ${ }^{32}$ were adopted and compared for the reacting free spray simulation cases. These four reduced mechanisms were all derived from the same detailed $n$-dodecane mechanism ${ }^{33}$ and validated extensively against the experimental data. Table 2 summarizes the species number and reaction number for these four mechanisms. Since of the four mechanisms, only Ren mech incorporated the polycyclic aromatic hydrocarbon (PAH) submechanism, for 


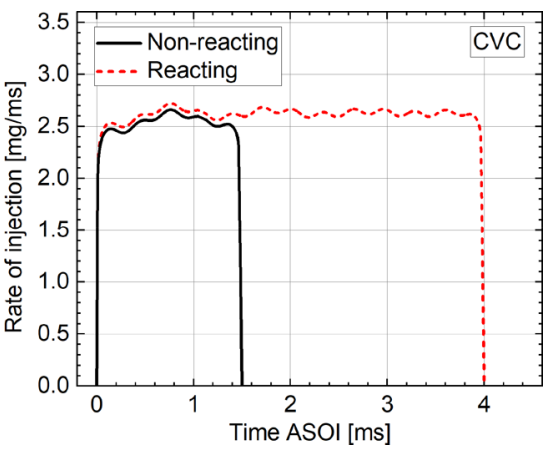

Figure 2. ROI profile adopted for the simulations.

Table 2. Summarization of the Four Reduced Mechanisms

$\begin{array}{lcc}\text { mechanism } & \text { no. of species } & \text { no. of reactions } \\ \text { Luo mech } & 105 & 420 \\ \text { Yao mech } & 54 & 268 \\ \text { Cai mech } & 57 & 197 \\ \text { Ren mech } & 178 & 758\end{array}$

consistency, only an empirical soot model (Hiroyasu-NSC) with acetylene as the precursor was utilized to model the soot formation and oxidation processes. ${ }^{34,35}$

3.2. Computational Meshes. A cylinder mesh with a dimension of $108 \times 108 \times 108 \mathrm{~mm}$ was adopted by following the previous work. ${ }^{36}$ A base mesh size of $2.0 \mathrm{~mm}$ with a fixed embedding region (refined scale of 3.0) downstream of the nozzle tip was adopted, which generates a minimum mesh size of $0.25 \mathrm{~mm}$. In addition, the adaptive mesh refinement (AMR) model was activated to automatically refine the mesh during the calculation. As proposed by the previous works, ${ }^{20,27}$ an AMR scale of 3.0 was adopted with velocity and temperature as the refined targets. Figure 3 shows the computational meshes for the free spray and DFI cases.

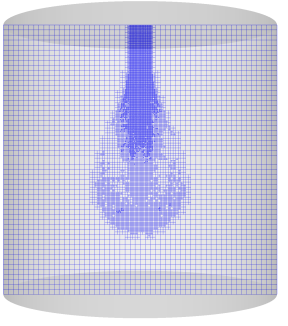

(a) Mesh 1

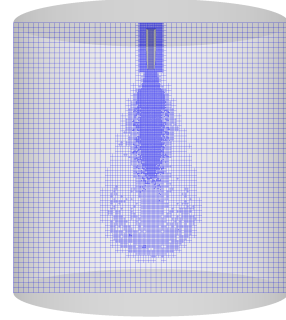

(b) Mesh 2 .
Figure 3. $(a, b)$ Schematic of the computational meshes.

3.3. Post-Processing Method. Tang et al. ${ }^{38}$ proposed a post-processing method based on Cantera to analyze the chemical kinetics processes for 3D CFD simulation cases. This method can identify the representative reactions for the fuel consumption and heat release in each computational cell. However, due to the limit of Cantera, some reversible reactions were taken as separated reactions, which is not appropriate enough when calculating the representative reactions. By following the rules of Chemkin, ${ }^{39}$ this issue is solved in this work, and the improved code is provided as the Supporting Information.

Figure 4 shows a schematic of this method. Briefly, the theory is to recalculate the instantaneous chemical heat release

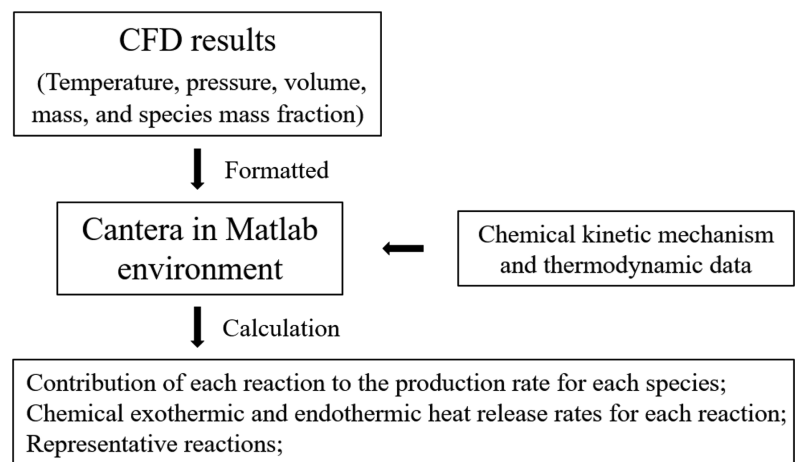

Data extraction

Data processing for visualization

Figure 4. Schematic of the post-processing method.

source in the energy equation as post-processing since the large-scale simulation does not store all information in the data output. Using the same chemical kinetic mechanism and solution variables, the production rate for each species and the heat release rate (HRR) for each reaction are computed for further analysis. In the following, the reaction that yields the highest HRR is denoted as REXR.

\section{RESULTS AND DISCUSSIONS}

4.1. Spray Penetration Validation. A sensitivity study of spray penetrations to the spray model parameters was

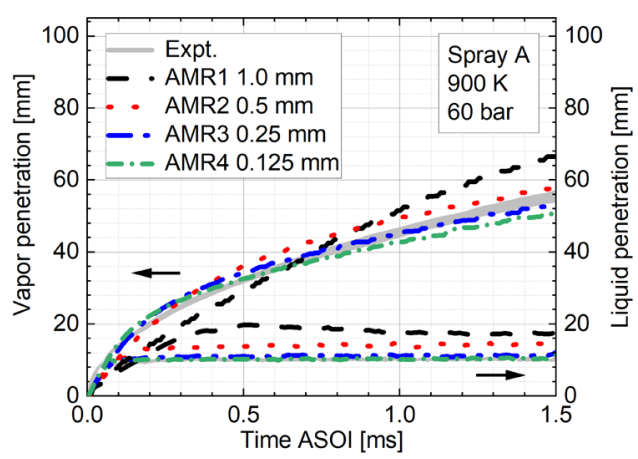

Figure 5. Predicted liquid and vapor penetration lengths for the spray A case with different AMR scales.

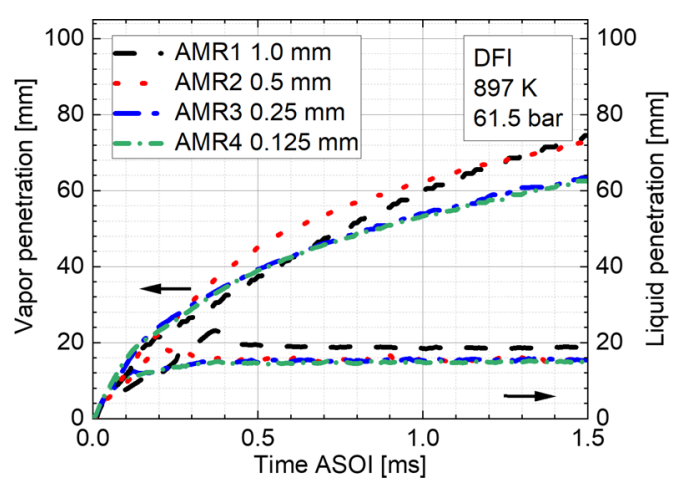

Figure 6. Predicted liquid and vapor penetration lengths for the DFI case with different AMR scales.

performed in the previous work, ${ }^{21}$ based on which a shed factor of 0.1 , a cutoff factor of 0.05 , and a $B_{1}$ of 6.8 were 


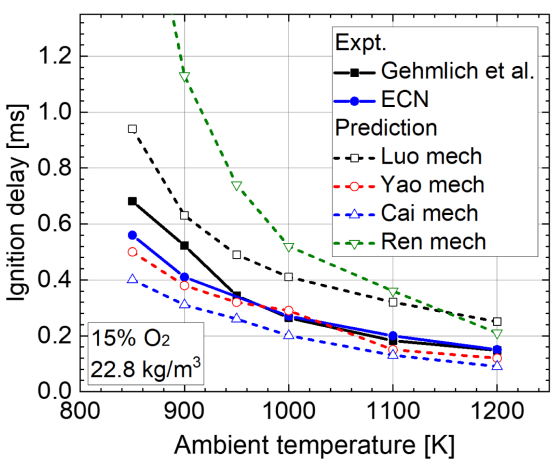

(a) Predicted ignition delays.

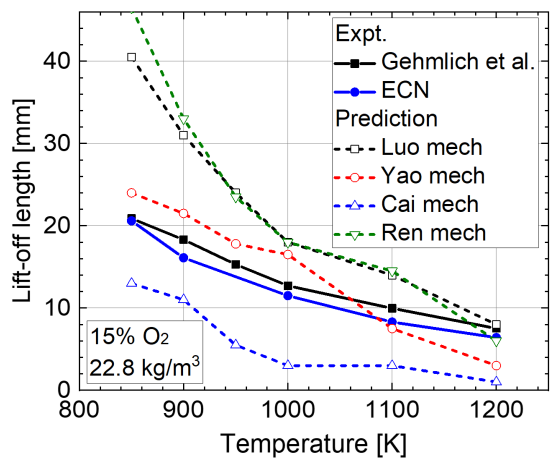

(b) Predicted lift-off lengths.

Figure 7. $(\mathrm{a}, \mathrm{b})$ Predicted ignition delays and lift-off lengths using different reduced mechanisms.

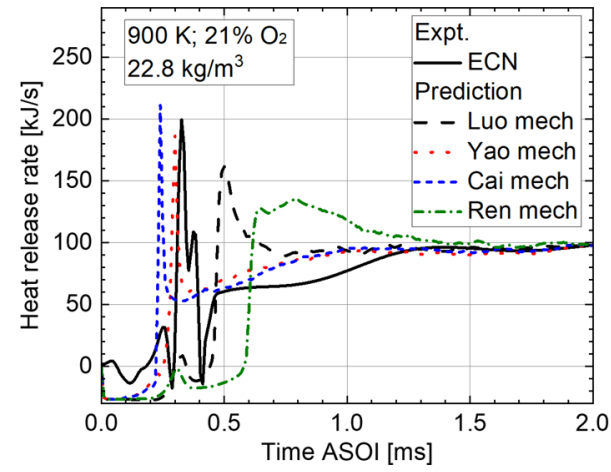

Figure 8. Predicted heat release rates using different reduced mechanisms.

selected. In this section, a further sensitivity study using different AMR scales ranging from 1 to 4 was conducted, which generates the minimum mesh sizes from 1.0 to 0.125 $\mathrm{mm}$, respectively.

Figure 5 compares the experimental and predicted spray penetration results using four different AMR scales. Liquid and vapor penetration lengths are defined as the farthest axial distances from the injector tip to the locations where $97 \%$ (mass fraction) of the total liquid fuel is encompassed and $0.1 \%$ (mass fraction) of the total fuel vapor is obtained, respectively. As seen in this figure, the predicted liquid and vapor penetrations show significant sensitivity to different AMR scales. The larger AMR scale leads to lower predicted penetration lengths. Note that similar predicted results are obtained when minimum mesh sizes of $0.25 \mathrm{~mm}$ or finer are

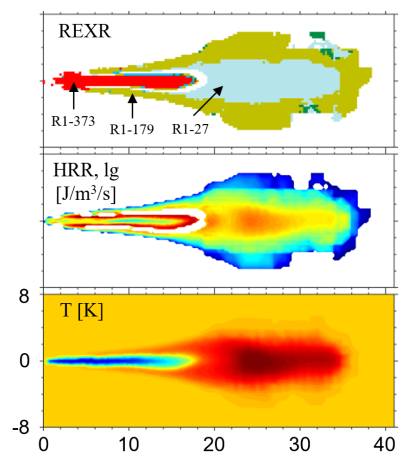

(a) Luo mech.

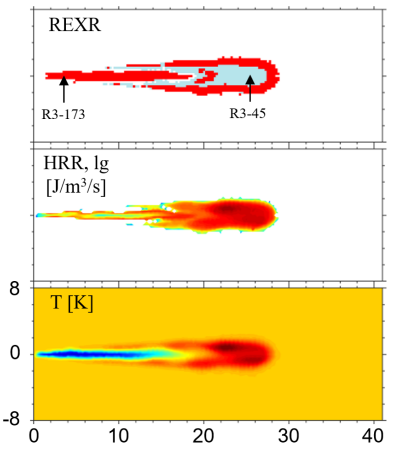

(c) Cai mech.

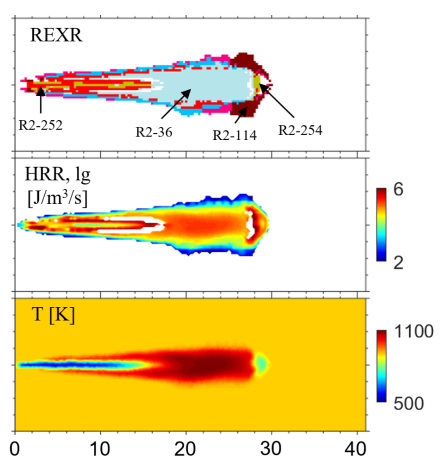

(b) Yao mech

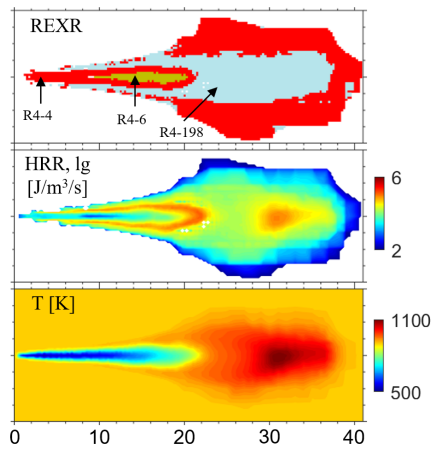

(d) Ren mech.
Figure 9. $(a-d)$ Comparison of the predicted distributions of REXR, $H R R$, and temperature during the ignition period with four different reduced mechanisms. The axis unit is in $\mathrm{mm}$.

adopted, which is in agreement with the work of Senecal et al. $^{37}$ Consequently, an AMR scale of 3 was utilized in the following sections.

To further confirm that an AMR scale of 3 is also able to reach the convergent result for the DFI case, another mesh sensitivity study is conducted. Figure 6 compares the predicted spray penetration results for the non-reacting DFI case using four different AMR scales. Similar to the above free spray cases, a higher AMR scale generates shorter spray penetrations. In addition, the case with an AMR scale of 3 predicts similar spray penetrations with an AMR scale of 4, indicating that a convergent result is obtained. Note that compared to the free spray case, the DFI case generates longer liquid and vapor penetrations, which will have a significant impact on the sprayflame structure and soot formation under reacting conditions.

4.2. Reacting Free Spray. 4.2.1. Validation of Experimental Data. In this section, four different reduced mechanisms (Luo mech, Yao mech, Cai mech, and Ren mech) were adopted to predict the reacting free spray cases. Experimental data from the work of Gehmlich et al. ${ }^{14}$ and the ECN website were collected for validations. Note that the injector (serial \#375020) with a nozzle hole diameter of $90 \mu \mathrm{m}$ from the work of Gehmlich et al. ${ }^{14}$ was used in the model, which is slightly different from the injector (serial \#210370) with a nozzle hole diameter of $91 \mu \mathrm{m}$ from the ECN website. The slight discrepancy has a limited impact on the simulation results. In the simulation, the ignition delay is defined as the time interval from the start of injection timing to the time when the ignition temperature $\left(T_{\mathrm{ign}}\right)$ is reached. The ignition temperature is defined as $T_{\mathrm{ign}}=0.5 \times\left(T_{\mathrm{amb}}+T_{\text {peak }}\right){ }^{40} \mathrm{In}$ addition, the lift-off length is defined as the distance from the 
Table 3. Key Reactions and Color Code

\begin{tabular}{|c|c|c|c|c|c|}
\hline \multicolumn{6}{|c|}{ (1) Luo mech } \\
\hline R1-27 & $\square$ & $\mathrm{HCO}+\mathrm{O}_{2}=\mathrm{CO}+\mathrm{HO}_{2}$ & R1-179 & $\square$ & $\mathrm{NC}_{3} \mathrm{H}_{7} \mathrm{O}_{2}=\mathrm{NC}_{3} \mathrm{H}_{7}+\mathrm{O}_{2}$ \\
\hline R1-373 & a & $\mathrm{C}_{12} \mathrm{H}_{25}-6+\mathrm{O}_{2}=\mathrm{C}_{12} \mathrm{H}_{25} \mathrm{O}_{2}-6$ & & & \\
\hline \multicolumn{6}{|c|}{ (2) Yao mech } \\
\hline $\mathrm{R} 2-3$ & $\square$ & $\mathrm{OH}+\mathrm{H}_{2}=\mathrm{H}_{2} \mathrm{O}+\mathrm{H}$ & R2-4 & ש & $\mathrm{OH}+\mathrm{OH}=\mathrm{O}+\mathrm{H}_{2} \mathrm{O}$ \\
\hline $\mathrm{R} 2-8$ & & $\mathrm{HO}_{2}+\mathrm{OH}=\mathrm{H}_{2} \mathrm{O}+\mathrm{O}_{2}$ & $\mathrm{R} 2-18$ & 口 & $\mathrm{OH}+\mathrm{OH}(+\mathrm{M})=\mathrm{H}_{2} \mathrm{O}_{2}(+\mathrm{M})$ \\
\hline $\mathrm{R} 2-20$ & $\square$ & $\mathrm{H}+\mathrm{OH}+\mathrm{M}=\mathrm{H}_{2} \mathrm{O}+\mathrm{M}$ & R2-36 & $\square$ & $\mathrm{HCO}+\mathrm{O}_{2}=\mathrm{CO}+\mathrm{HO}_{2}$ \\
\hline R2-63 & $\square$ & $\mathrm{CH}_{2} \mathrm{O}+\mathrm{OH}=\mathrm{HCO}+\mathrm{H}_{2} \mathrm{O}$ & R2-66 & $\square$ & $\mathrm{CH}_{3}+\mathrm{H}(+\mathrm{M})=\mathrm{CH}_{4}(+\mathrm{M})$ \\
\hline R2-114 & $\mathbf{m}$ & $\mathrm{CH}_{2} \mathrm{CHO}+\mathrm{O}_{2}=\mathrm{CH}_{2} \mathrm{O}+\mathrm{CO}+\mathrm{OH}$ & R2-143 & m & $\mathrm{AC}_{3} \mathrm{H}_{5}+\mathrm{H}(+\mathrm{M})=\mathrm{C}_{3} \mathrm{H}_{6}(+\mathrm{M})$ \\
\hline R2-252 & $\square$ & $\mathrm{PXC}_{12} \mathrm{H}_{25}+\mathrm{O}_{2}=\mathrm{C}_{12} \mathrm{H}_{25} \mathrm{O}_{2}$ & $\mathrm{R} 2-254$ & $\square$ & $\mathrm{S} 3 \mathrm{XC}_{12} \mathrm{H}_{25}+\mathrm{O}_{2}=\mathrm{C}_{12} \mathrm{H}_{25} \mathrm{O}_{2}$ \\
\hline $\mathrm{R} 2-260$ & $\square$ & $\mathrm{O}_{2} \mathrm{C}_{12} \mathrm{H}_{24} \mathrm{OOH}=\mathrm{OC}_{12} \mathrm{H}_{23} \mathrm{OOH}+\mathrm{OH}$ & & & \\
\hline \multicolumn{6}{|c|}{ (3) Cai mech } \\
\hline R3-45 & $\square$ & $\mathrm{HCO}+\mathrm{O}_{2}=>\mathrm{CO}+\mathrm{HO}_{2}$ & R3-173 & $\square$ & $\mathrm{C}_{12} \mathrm{H}_{25}+\mathrm{O} 2<=>\mathrm{C}_{12} \mathrm{H}_{25} \mathrm{O}_{2}$ \\
\hline \multicolumn{6}{|c|}{ (4) Ren mech } \\
\hline R4-4 & $\mathbf{m}$ & $\mathrm{C}_{12} \mathrm{H}_{25}+\mathrm{O}_{2}=\mathrm{C}_{12} \mathrm{H}_{25} \mathrm{OO}$ & R4-6 & $\square$ & $\mathrm{C}_{12} \mathrm{H}_{24} \mathrm{OOH}+\mathrm{O}_{2}=\mathrm{OOC}_{12} \mathrm{H}_{24} \mathrm{OOH}$ \\
\hline R4-198 & $\square$ & $\mathrm{HCO}+\mathrm{O}_{2}=\mathrm{CO}+\mathrm{HO}_{2}$ & & & \\
\hline
\end{tabular}

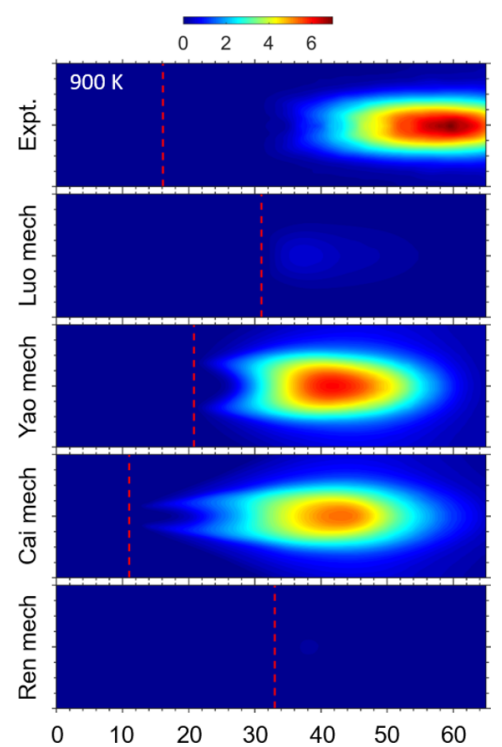

Figure 10. Predicted soot formation by using different reduced mechanisms. The red line represents the lift-off length. The axis unit is in $\mathrm{mm}$. Experimental data is from the ECN website. ${ }^{22}$

injector tip to the nearest location where $2 \%$ of the peak $\mathrm{OH}$ mass fraction is obtained. ${ }^{41}$

Figure 7 compares the experimental and predicted ignition delays and lift-off lengths. The four different reduced mechanisms predict similar trends. A higher ambient temperature leads to lower ignition delay and shorter lift-off length. Differently, ignition delays are reasonably captured by the Yao mech, under-predicted by the Cai mech, and significantly overpredicted by the Luo mech and Ren mech. In addition, Yao mech also demonstrates the best-predicted performance for lift-off length, despite that it over-predicts the lift-off lengths at temperatures lower than $1100 \mathrm{~K}$ and under-predicts the lift-off lengths at temperatures higher than $1100 \mathrm{~K}$.

4.2.2. Analysis of Chemical Kinetics. Figure 8 compares the experimental and predicted heat release rates. The experimental HRR is obtained from the ECN website. ${ }^{22}$ Note that all reduced mechanisms capture the HRR value during the

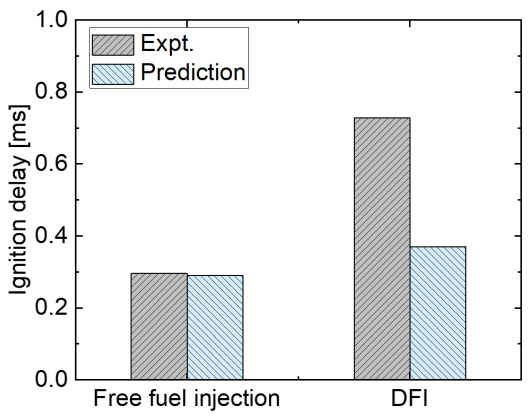

(a) Predicted ignition delays.

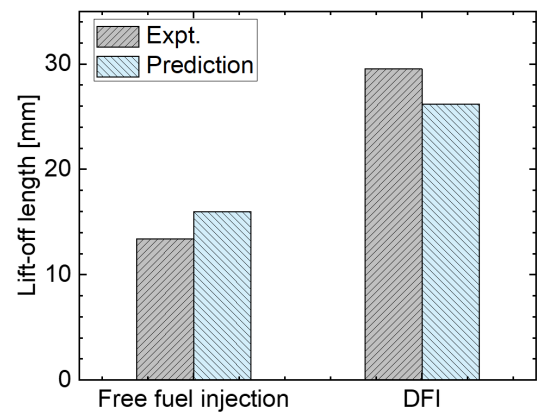

(b) Predicted lift-off lengths.

Figure 11. (a,b) Predicted ignition delays and lift-off lengths for the free fuel injection and DFI cases.

steady diffusion combustion period. For the ignition behavior, Yao mech predicted the closest ignition delay and peak HRR value with the experiment.

To further compare the chemical kinetics processes during the ignition period using different reduced mechanisms, the post-processing code was utilized for analysis. Four different combustion timings, i.e., 0.46, 0.29, 0.24, and $0.59 \mathrm{~ms}$, were selected for the four cases, which correspond to the timings when a peak temperature of $1100 \mathrm{~K}$ was achieved. Figure 9 compares the predicted distributions of REXR, HRR, and temperature $(T)$ using different reduced mechanisms. Note 


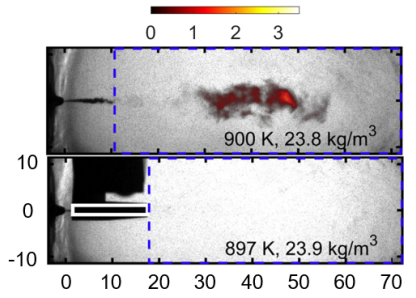

(a) Measured soot [KFL].

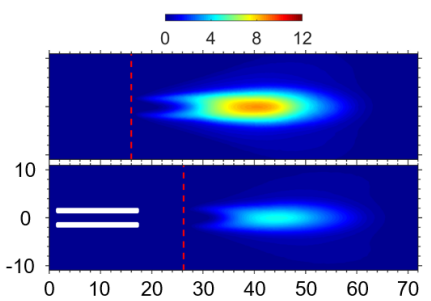

(b) Predicted soot [ppm].
Figure 12. (a,b) Comparison of the experimental and predicted distributions of soot formation for the free spray (above) and DFI (below) cases at about $3.0 \mathrm{~ms}$. The axis unit is in $\mathrm{mm}$. Experimental data are from Gehmlich et al. ${ }^{14}$

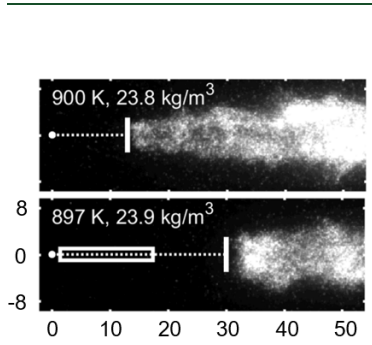

(a) Measured $\mathrm{OH}^{*}$ intensity.

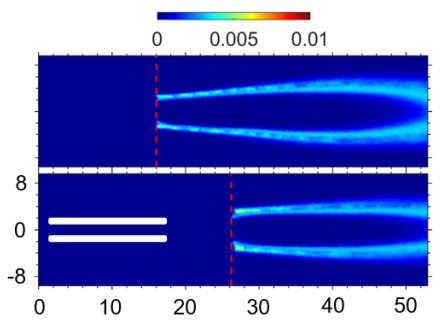

(b) Predicted $\mathrm{OH}$ mass fraction.
Figure 13. (a,b) Comparison of experimentally measured $\mathrm{OH}^{*}$ intensity at about $3.0 \mathrm{~ms}$ and the predicted distributions of the mass fraction of $\mathrm{OH}$ for the free spray (above) and DFI (below) cases. The red line represents the predicted lift-off length. Axis unit in $\mathrm{mm}$. Experimental data are from Gehmlich et al. ${ }^{14}$

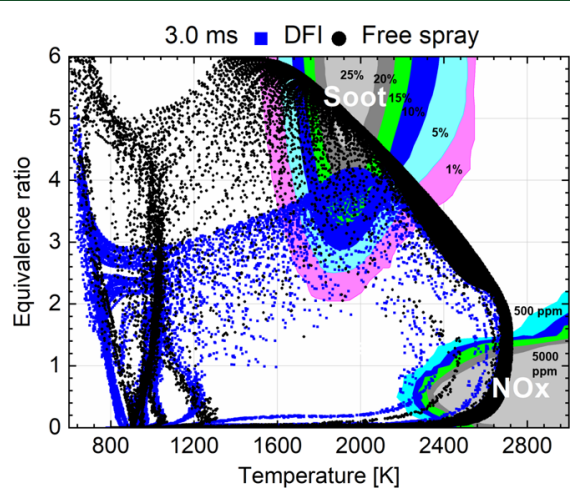

Figure 14. Comparison of the predicted distributions of the temperature-equivalence ratio for the DFI and free spray cases at $3.0 \mathrm{~ms}$

that for the calculations of REXR and HRR, only the regions with $\mathrm{HRR}$ higher than $100 \mathrm{~J} / \mathrm{m}^{3} / \mathrm{s}$ are sampled. Table 3 summarizes the key reactions of this work.

Figure 9 shows that the high-temperature ignitions using different reduced mechanisms are all triggered downstream of the spray-flame structure. Note that different cases demonstrate a similar heat release feature, which primarily includes two regions, i.e., the inner low-temperature heat release region and the downstream higher-temperature heat release region. The low-temperature heat release is dominated by the $\mathrm{O}_{2}$ addition reactions (R1-373, R2-252, R3-173, and R4-4), and the higher-temperature heat release is dominated by the reaction $\mathrm{HCO}+\mathrm{O}_{2}=\mathrm{CO}+\mathrm{HO}_{2}(\mathrm{R} 1-27, \mathrm{R} 2-36, \mathrm{R} 3-45$, and $\mathrm{R} 4-198)$. This indicates that the fuel consumption reaction pathway is similar for the four reduced mechanisms.
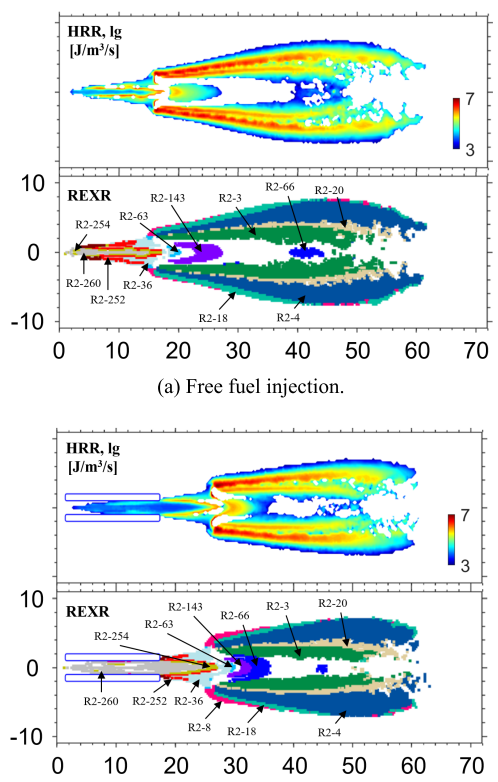

(b) DFI.

Figure 15. Comparison of the predicted distributions of HRR and REXR at $3.0 \mathrm{~ms}$ for (a) free fuel injection and (b) DFI cases. The axis unit is in $\mathrm{mm}$.

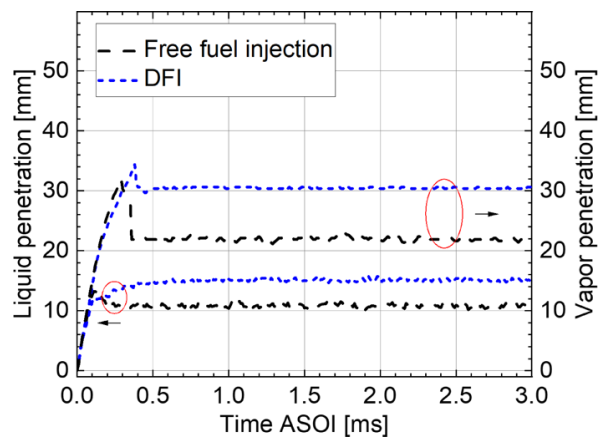

Figure 16. Comparison of the predicted liquid and vapor penetration lengths for the free spray and DFI cases.

4.2.3. Validation of Soot Distribution. Figure 10 compares the experimental and predicted soot formation. The experimental data is from the ECN website. ${ }^{22}$ The red lines represent the lift-off lengths. Note that the four different reduced mechanisms predict similar soot formation locations, in reasonable agreement with the experiment. However, both Luo mech and Ren mech predicted significantly lower soot formation compared to Yao mech and Cai mech, primarily due to longer predicted lift-off lengths and leaner mixture distributions. Overall, of the four reduced mechanisms, Yao mech predicts the most accurate lift-off length and soot formation. Based on the above results, Yao mech is used in subsequent simulations.

4.3. Ducted Fuel Injection. 4.3.1. Comparison with Free Spray. In this section, the free spray and DFI cases with a nominal ambient temperature of $900 \mathrm{~K}$ and an $\mathrm{O}_{2}$ concentration of $21 \%$ are simulated using the Yao mech. Note that the real ambient temperature for the DFI case is 897 $\mathrm{K}$, slightly lower than the nominal value, and the measured wall temperature is $461 \mathrm{~K}^{14}$ Figure 11 compares the experimental and predicted ignition delays and lift-off lengths for the free spray and DFI cases. The simulation is in good agreement with 


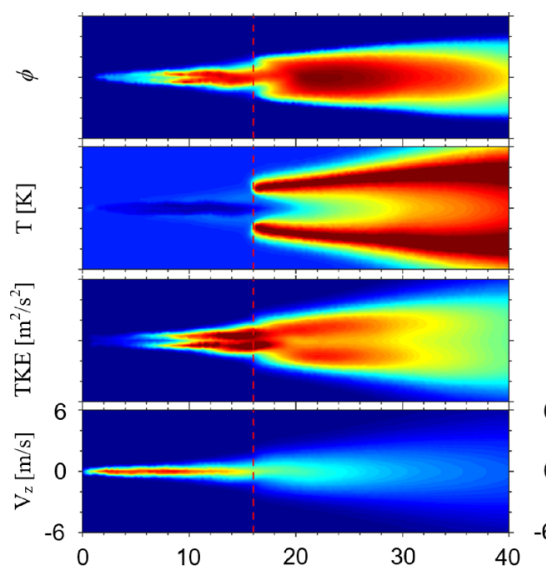

(a) Free fuel injection.

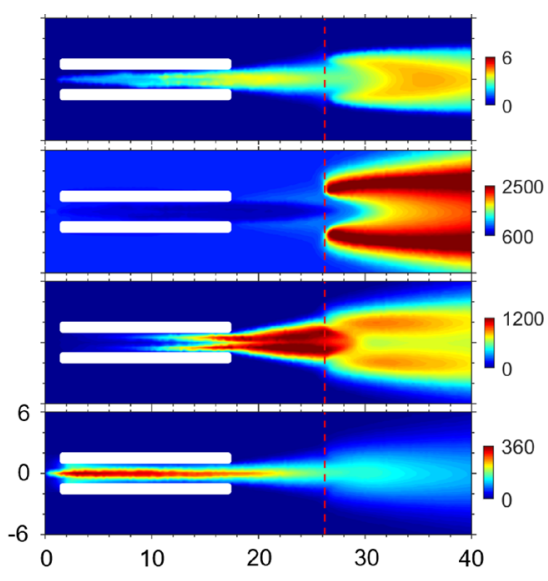

(b) DFI

Figure 17. (a,b) Comparison of the predicted distributions of $\phi, T$, TKE, and $V_{z}$ for the free spray and DFI cases on the central plane at 3.0 ms. The red line represents the lift-off length. The axis unit is in $\mathrm{mm}$.

experimental data for the free injection case, but it significantly under-predicts the ignition delay for the DFI case. There are possibly two primary factors that lead to the discrepancy, including the uncertainty of the initial temperature within the duct and ignorance of the turbulence-chemistry interaction effect. Nevertheless, the overall growing trend of both the ignition delay and lift-off length from the free spray case to the DFI case is well captured by the simulation.

Figures 12 and 13 compare the experimental and predicted distributions of soot and $\mathrm{OH}$ formation for the DFI and free spray cases at about $3.0 \mathrm{~ms}$. Only qualitative distributions of soot and $\mathrm{OH}^{*}$ intensity were measured in the experiment. ${ }^{14}$ It is seen that the simulations reasonably predict the distributions of soot and $\mathrm{OH}$. Compared to the free spray case, the DFI case has a significantly longer lift-off length and lower soot formation.

To explain the reduced soot formation for the DFI case, Figure 14 compares the predicted distributions of the temperature-equivalence ratio for the two cases. It is known that soot is primarily generated in the regions with high temperatures and rich mixture conditions. ${ }^{4,42}$ Due to a longer lift-off length, the DFI case yields an overall leaner air-fuel mixture than the free injection case, mostly at the equivalence ratio lower than 4.0. As a result, the DFI case results in significantly lower soot formation.

To understand the impact of DFI on the spray-flame structure, Figure 15a,b compares the predicted distributions of HRR and REXR for the free fuel injection and DFI cases at 3.0 ms. Note that only the regions with HRR higher than $1000 \mathrm{~J} /$ $\mathrm{m}^{3} / \mathrm{s}$ are depicted. Similar to the initial ignition period, there also exist a low-temperature region and an intermediate heat release region during the steady combustion period for the free spray case. Differently, during the steady diffusion combustion period, there exists a long high-temperature heat release region, with the heat release dominated by the hydrogen-oxygen reactions (R2-3, R2-4, and R2-20). In addition, owing to the diffusion combustion process, a rich region is formed within the flame core, with the heat release dominated by reaction $\mathrm{R} 2$ $143\left(\mathrm{AC}_{3} \mathrm{H}_{5}+\mathrm{H}(+\mathrm{M})=\mathrm{C}_{3} \mathrm{H}_{6}(+\mathrm{M})\right)$, which inhibits the rapid fuel consumption and promotes the formation of soot precursors. $^{43}$
Compared to the free spray case, the DFI case generates a significantly different spray-flame structure, featured with a longer low-temperature heat release region but a shorter hightemperature heat release region and a smaller core within these two regions. The smaller core region indicates that the DFI case has a lower sooting tendency. However, representative reactions that dominate the heat release process in these three regions are similar for these two cases.

4.3.2. Effects on Lift-Off Length. The above results indicate that a longer lift-off length leads to enhanced mixing and leaner mixture distribution for the DFI case. Therefore, the detailed underlying mechanism is investigated next. Figure 16 compares the predicted liquid and vapor penetration lengths for the free spray and DFI cases. During the steady spray combustion period, both the liquid and vapor penetrations for the DFI case are significantly longer than those for the free spray case. Note that the steady vapor penetrations for both the free spray and DFI cases are approximately $4 \mathrm{~mm}$ higher than the lift-off lengths, indicating that the lift-off length is related to the steady vapor penetration.

Figure 17 compares the predicted distributions of the equivalence ratio $(\phi)$, temperature $(T)$, turbulent kinetic energy (TKE), and the axial velocity $\left(V_{z}\right)$ on the central plane for the free spray and DFI cases at $3.0 \mathrm{~ms}$. Compared to the free spray case, the DFI case generates a significantly longer, leaner, and faster spray core jet. Figure 18 further shows that the TKE within the duct for the DFI case is significantly lower than that of the free spray case since the duct inhibits air entrainment. Consequently, the gas mixture is significantly leaner due to the reduced fuel evaporation, and the spray penetrates longer with a higher core velocity. Consequently, the leaner mixture inhibits the soot formation process. ${ }^{42}$ Also, note that $V_{z}$ for the DFI case remains high throughout the duct length. Moreover, heat transfer from ambient hot air is reduced so that the inner jet core maintains a low temperature even beyond the liquid penetration length (about $15 \mathrm{~mm}$ ). Therefore, a higher velocity and longer liquid penetration of the inner core jet lead to a longer ignition delay and lift-off length for the DFI case.

4.3.3. Effect of Initial Temperature within the Duct. In the previous simulation, the gas temperature within the chamber is considered homogeneous at an ambient temperature of $897 \mathrm{~K}$, while the chamber walls and duct walls (internal and external) 


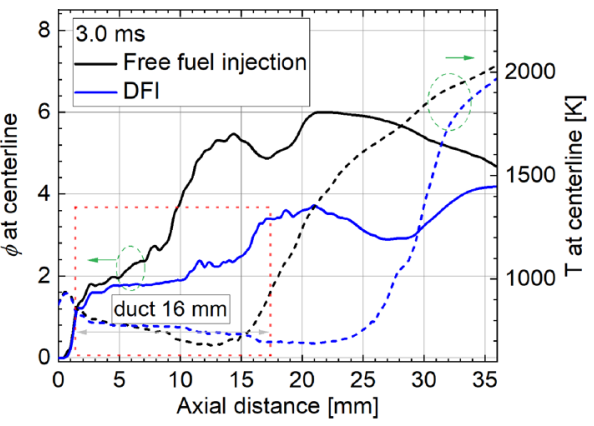

(a) $\phi$ and $\mathrm{T}$ at the centerline.

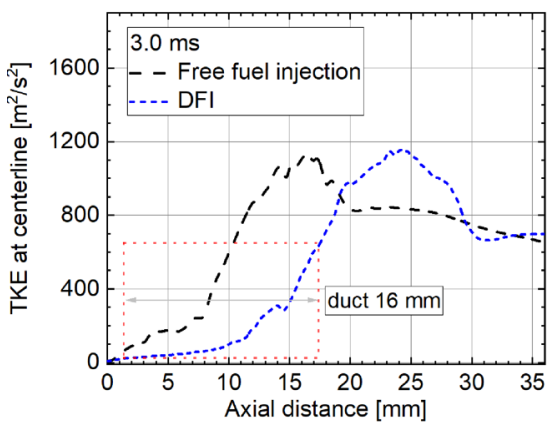

(b) TKE at the centerline.

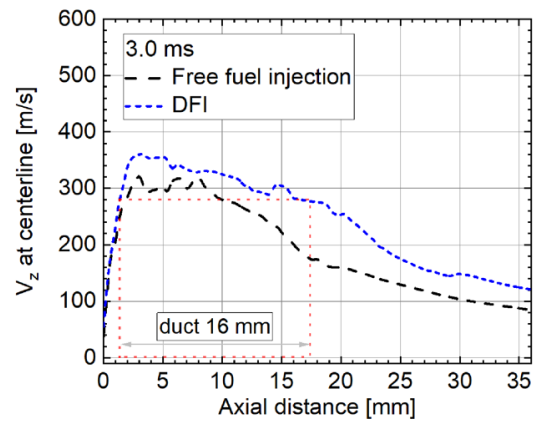

(c) $V_{z}$ at the centerline.

Figure 18. $(\mathrm{a}-\mathrm{c})$ Comparison of the predicted distributions of $\phi, T$, TKE, and $V_{z}$ for the free spray and DFI cases on the axial line at 3.0 ms.

are all set at $461 \mathrm{~K}^{13,14}$ However, the gas temperature within the duct may be significantly affected by the heat transfer to the duct walls ${ }^{14,16}$ since the duct has a small diameter $(2 \mathrm{~mm})$ but a relatively long length $(16 \mathrm{~mm})$. Although the ambient temperature is high, after a long time when the entire system reaches a thermal equilibrium state before the injection, the gas temperature within the duct may be significantly lower than the ambient temperature.

Since it is difficult to directly measure the gas temperature distribution within the duct, in the simulations, various initial gas temperatures within the duct are compared. Computationally, the confined space within the inner duct wall is taken as a separate region, which is initialized with the same pressure as the chamber but at different temperatures $(600,700,800$, and $897 \mathrm{~K})$. The inner duct wall is still kept at $461 \mathrm{~K}$.

Figure 19 compares the predicted ignition delays and lift-off lengths with different initial temperatures within the duct. It is found that the predicted ignition delays are prolonged significantly with an initial lower temperature within the

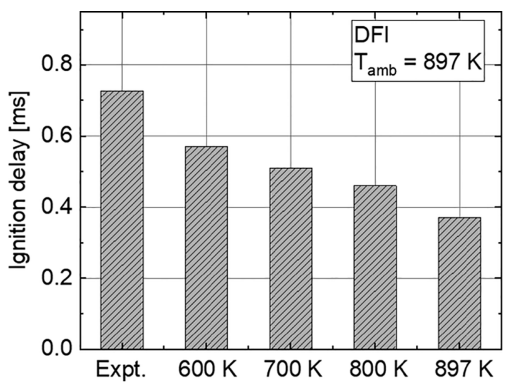

(a) Predicted ignition delays

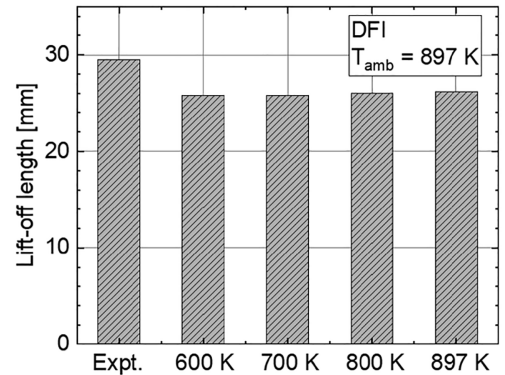

(b) Predicted lift-off lengths.

Figure 19. $(a, b)$ Comparison of the predicted ignition delays and liftoff lengths with different initial temperatures within the duct.

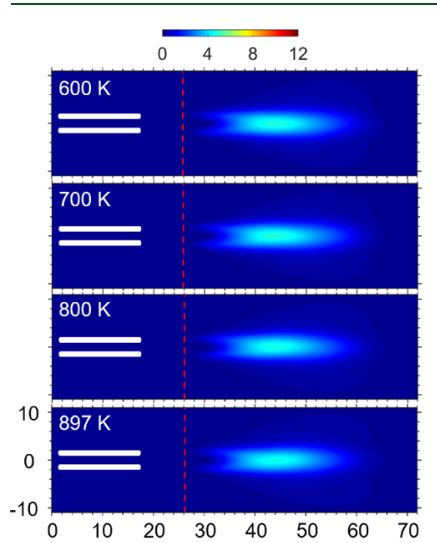

(a) Soot volume fraction [ppm].

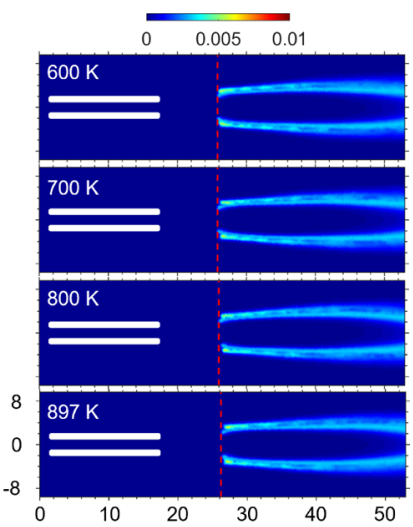

(b) $\mathrm{OH}$ mass fraction
Figure 20. $(a, b)$ Predicted distributions of the soot volume fraction and $\mathrm{OH}$ mass fraction at $3.0 \mathrm{~ms}$ with different initial temperatures within the duct. The red line represents the lift-off length. The axis unit is in $\mathrm{mm}$.

duct. However, the lift-off length is almost unaffected by the change. Figure 20 further compares the predicted distributions of the soot volume fraction and $\mathrm{OH}$ mass fraction with different initial temperatures within the duct. Despite the differences in the ignition delay, almost no changes in the liftoff length are found.

To understand the effect of initial temperature within the duct on the ignition process, Figure 21 compares the predicted distributions of temperature and the equivalence ratio at 0.3 ms (before ignition) for various cases. A lower initial temperature within the duct results in a lower average temperature before ignition, which leads to a longer ignition delay eventually. Figure 22 shows the predicted distributions of the equivalence ratio and temperature at $0.3 \mathrm{~ms}$ for different 


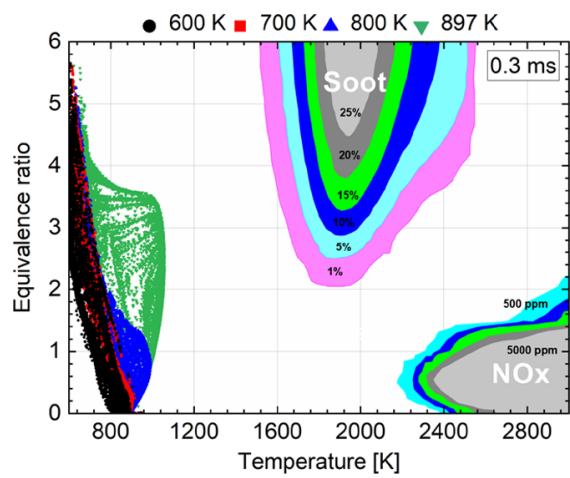

Figure 21. Comparison of the predicted distributions of the temperature-equivalence ratio at $0.3 \mathrm{~ms}$ with different initial temperatures within the duct.

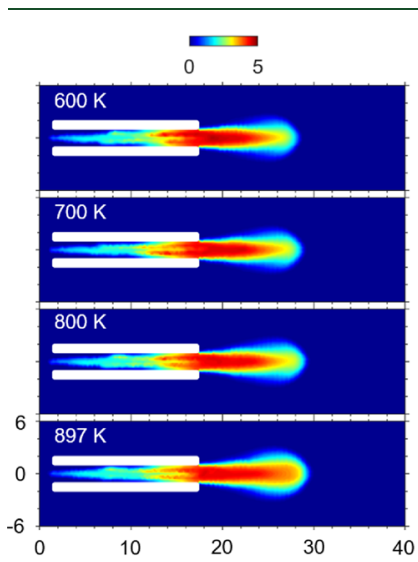

(a) $\phi$

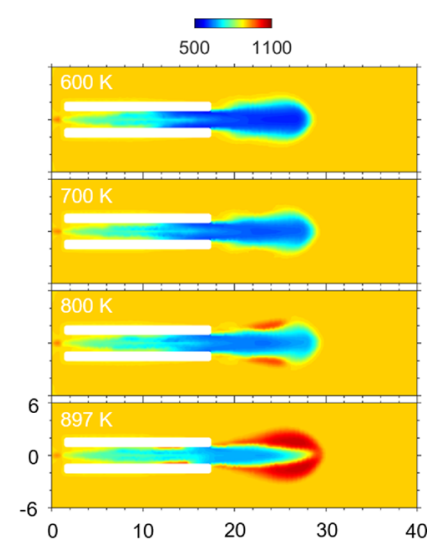

(b) $\mathrm{T}[\mathrm{K}]$
Figure 22. (a,b) Comparison of the predicted distributions of $\phi$ and $T$ at $0.3 \mathrm{~ms}$ with different initial temperatures within the duct. The axis unit is in $\mathrm{mm}$.

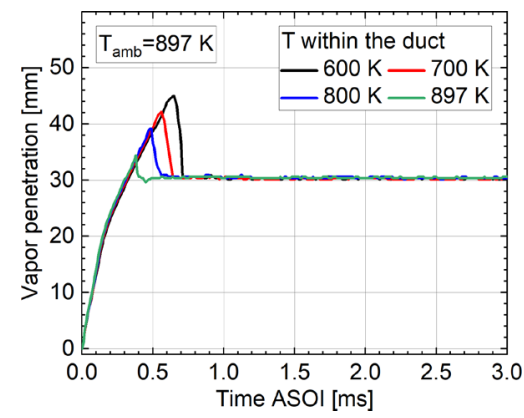

Figure 23. Comparison of the predicted vapor penetration lengths with different initial temperatures within the duct.

cases. With a higher initial temperature within the duct, the fuel vapor penetration is longer. This is primarily because the initial higher gas temperature leads to a lower gas density and thus a lower resistance within the duct.

Figure 23 compares the temporal evolution of the vapor penetration lengths for the four cases. Owing to a lower air resistance, a higher initial temperature within the duct leads to a slightly higher peak vapor penetration before ignition. Note that the ignition delay coincides well with the abrupt decline of the vapor penetration due to the rapid consumption of the fuel-air mixture during the high-temperature heat release period. Beyond the ignition period, however, the liquid and

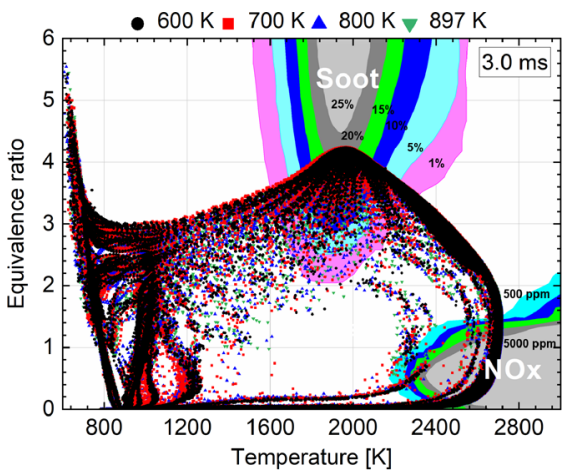

Figure 24. Comparison of the predicted distributions of the temperature-equivalence ratio at $3.0 \mathrm{~ms}$ with different initial temperatures within the duct.

vapor penetrations during the steady combustion period are nearly identical for all cases, resulting in similar lift-off lengths. Figure 24 further compares the predicted distributions of temperature and the equivalence ratio at $3.0 \mathrm{~ms}$. Unlike Figure 21 at an earlier time, the distributions are similar for all cases, confirming that the cooling of the gases inside the duct hardly affects the flame lift-off and steady combustion behavior. This is not surprising since most of the initial gas within the duct has already been pushed out of the duct and then consumed by the combustion process. Consequently, during the steady combustion period, the flow field and spray-flame structure are dominated by the injection process only, which are similar for the different cases.

\section{CONCLUSIONS AND FUTURE WORK}

This work numerically investigated the free spray and DFI strategies in a constant volume chamber. Four different reduced $n$-dodecane mechanisms were adopted and evaluated for the spray A simulations. A comparative study between the free spray and DFI strategies was then conducted. Key findings are summarized as follows.

(1) Of the four reduced $n$-dodecane mechanisms, Yao mech demonstrated the best-predicted results of ignition delay, lift-off length, and soot formation.

(2) The duct inhibited the air entrainment process and promoted the jet velocity, which led to a longer liquid penetration, ignition delay, and lift-off length. Therefore, the DFI method produced the overall leaner mixture distribution and lower soot formation compared to the free spray case.

(3) Compared to the free spray case, the DFI case generated a significantly longer low-temperature heat release region but a shorter high-temperature heat release region and a smaller core between these two regions, which helps to inhibit the formation of soot precursors.

(4) A lower initial temperature within the duct led to a lower mixture reactivity and thus a longer ignition delay. However, this effect vanished after the lifted flame was established, such that the lift-off length was hardly affected by the initial gas cooling inside the duct.

Based on the results of this work, there are still some issues to be resolved both numerically and experimentally. First, the turbulence-chemistry interaction effect needs to be considered to better predict the spray-flame structure and soot formation. Second, more experimental data need to be collected to 
calibrate the spray mixture distribution using the DFI method. More importantly, since a leaner air-fuel mixture is generated, the $\mathrm{CO}$ and hydrocarbon emissions could be an issue for practical applications. Therefore, metal engine experiments over a wide load range should be conducted to fully evaluate the effect of the DFI method on engine combustion performance and emissions (soot, $\mathrm{NO} x, \mathrm{CO}$, and hydrocarbons).

\section{ASSOCIATED CONTENT}

\section{(s) Supporting Information}

The Supporting Information is available free of charge at https://pubs.acs.org/doi/10.1021/acs.energyfuels.0c02757.

Matlab code (PDF)

\section{AUTHOR INFORMATION}

\section{Corresponding Author}

Xinlei Liu - Clean Combustion Research Center (CCRC), King Abdullah University of Science and Technology (KAUST), Thuwal 23955, Saudi Arabia; (1) orcid.org/0000-0002-37630749; Email: xinlei.liu@kaust.edu.sa

\section{Authors}

Balaji Mohan - Transport Technologies Division, R\&DC, Saudi Aramco, Dhahran, Saudi Arabia

Hong G. Im - Clean Combustion Research Center (CCRC), King Abdullah University of Science and Technology (KAUST), Thuwal 23955, Saudi Arabia

Complete contact information is available at: https://pubs.acs.org/10.1021/acs.energyfuels.0c02757

\section{Notes}

The authors declare no competing financial interest.

\section{ACKNOWLEDGMENTS}

The computational simulations utilized the clusters at the KAUST Supercomputing Laboratory. The authors thank the Convergent Science, Inc. for providing the CONVERGE license.

\section{NOMENCLATURE}

$3 \mathrm{D}=$ three-dimensional
$\mathrm{AMR}=$ adaptive mesh refinement
$\mathrm{CFD}=$ computational fluid dynamics
$\mathrm{CI}=$ compression ignition
$\mathrm{CVC}=$ constant volume chamber
$\mathrm{DFI}=$ ducted fuel injection
$\mathrm{DPF}=$ diesel particulate filter
$\mathrm{ECN}=$ Engine Combustion Network
$\mathrm{EGR}=$ exhaust gas recirculation
$\mathrm{HRR}=$ heat release rate
ICE = internal combustion engine
$\phi=$ equivalence ratio
LTC = low-temperature combustion
NO $x=$ nitric oxides
PAH = polycyclic aromatic hydrocarbons
RNG = renormalization group
ROI = rate of injection
SCR = selective catalytic reduction
SI = spark-ignited
SOI = start of injection
spray A = n-dodecane spray

$T=$ temperature

TKE = turbulent kinetic energy

$T_{\text {ign }}=$ ignition temperature

$V_{z}=$ axial velocity

\section{REFERENCES}

(1) Reitz, R. D.; Ogawa, H.; Payri, R.; Fansler, T.; Kokjohn, S.; Moriyoshi, Y.; Agarwal, A.; Arcoumanis, D.; Assanis, D.; Bae, C.; Boulouchos, K.; Canakci, M.; Curran, S.; Denbratt, I.; Gavaises, M.; Guenthner, M.; Hasse, C.; Huang, Z.; Ishiyama, T.; Johansson, B.; Johnson, T. V.; Kalghatgi, G.; Koike, M.; Kong, S. C.; Leipertz, A.; Miles, P.; Novella, R.; Onorati, A.; Richter, M.; Shuai, S.; Siebers, D.; Su, W.; Trujillo, M.; Uchida, N.; Vaglieco, B. M.; Wagner, R. M.; Zhao, H. IJER editorial: The future of the internal combustion engine. Int. J. Engine Res. 2020, 21, 3-10.

(2) Tekgül, B.; Kahila, H.; Kaario, O.; Vuorinen, V. Large-eddy simulation of dual-fuel spray ignition at different ambient temperatures. Combust. Flame 2020, 215, 51-65.

(3) Lechner, G.A.; Jacobs, T. J.; Chryssakis, C. A.; Assanis, D. N.; Siewert, R. M., Evaluation of a narrow spray cone angle, advanced injection timing strategy to achieve partially premixed compression ignition combustion in a diesel engine In SAE Technical Paper; SAE International: 2005, 394-404.

(4) Akihama, K.; Takatori, Y.; Inagaki, K.; Sasaki, S.; Dean, A., Mechanism of the smokeless rich diesel combustion by reducing temperature. In SAE Technical Paper; SAE International: 2001, 648662.

(5) Dec, J.E., A conceptual model of DI diesel combustion based on laser-sheet imaging. In SAE Technical Paper; SAE International: 1997, 1319-1348.

(6) Musculus, M. P. B.; Miles, P. C.; Pickett, L. M. Conceptual models for partially premixed low-temperature diesel combustion. Prog. Energy Combust. Sci. 2013, 39, 246-283.

(7) Mao, B.; Yao, M.; Zheng, Z.; Li, Y.; Liu, H.; Yan, B. Effects of dual loop EGR on performance and emissions of a diesel engine. In SAE Technical Paper; SAE International: 20152015-01-0873.

(8) Dec, J. E.; Yang, Y. Boosted HCCI for high power without engine knock and with ultra-low NOx emissions - using conventional gasoline. SAE Int. J. Engines 2010, 750-767. 2010-01-1086

(9) Manente, V.; Johansson, B.; Tunestal, P.; Cannella, W. J. Influence of inlet pressure, EGR, combustion phasing, speed and pilot ratio on high load gasoline partially premixed combustion. In $S A E$ Technical Paper; SAE International: 2010. 2010-01-1471

(10) Nilsen, C. W.; Biles, D. E.; Mueller, C. J. Using ducted fuel injection to attenuate soot formation in a mixing-controlled compression ignition engine. SAE Int. J. Engines 2019, 12, 309-322.

(11) Tan, J.; Solbrig, C.; Schmieg, S.J. The development of advanced 2-way SCR/DPF systems to meet future heavy-duty diesel emissions. In SAE Technical Paper; SAE International: 2011. 2011-01-1140

(12) Yang, Y.; Cho, G.; Rutland, C. Model based study of DeNOx characteristics for integrated DPF/SCR system over Cu-Zeolite. In SAE Technical Paper; SAE International: 2015. 2015-01-1060

(13) Mueller, C. J.; Nilsen, C. W.; Ruth, D. J.; Gehmlich, R. K.; Pickett, L. M.; Skeen, S. A. Ducted fuel injection: A new approach for lowering soot emissions from direct-injection engines. Appl. Energy 2017, 204, 206-220.

(14) Gehmlich, R. K.; Mueller, C. J.; Ruth, D. J.; Nilsen, C. W.; Skeen, S. A.; Manin, J. Using ducted fuel injection to attenuate or prevent soot formation in mixing-controlled combustion strategies for engine applications. Appl. Energy 2018, 226, 1169-1186.

(15) Svensson, K. I.; Martin, G. C. Ducted fuel injection: Effects of stand-off distance and duct length on soot reduction. In SAE Technical Paper; SAE International: 2019 2019-01-0545.

(16) Fitzgerald, R. P.; Svensson, K.; Martin, G.; Qi, Y.; Koci, C. Early investigation of ducted fuel injection for reducing soot in mixing-controlled diesel flames. SAE Int. J. Engines 2018, 817. 201801-0238 
(17) Li, F.; Lee, C.-f.; Wu, H.; Wang, Z.; Liu, F. An optical investigation on spray macroscopic characteristics of ducted fuel injection. Exp. Therm. Fluid Sci. 2019, 109, 109918.

(18) Li, F.; Lee, C.-f.; Wang, Z.; Liu, F.; Lu, G. Optical investigation on impacts of ambient pressure on macroscopic spray characteristics of ducted fuel injection under non-vaporizing conditions. Fuel 2020, 268, 117192.

(19) Li, F.; Lee, C.-f.; Wang, Z.; Wu, H.; Lu, G. Schlieren investigation on impacts of duct size on macroscopic spray characteristics of ducted fuel injection. Appl. Therm. Eng. 2020, 176, 115440 .

(20) Liu, X.; Kokjohn, S.; Li, Y.; Wang, H.; Li, H.; Yao, M. A numerical investigation of the combustion kinetics of reactivity controlled compression ignition (RCCI) combustion in an optical engine. Fuel 2019, 241, 753-766.

(21) Liu, X.; Wang, H.; Zhang, Y.; Yao, M. A numerical investigation on the chemical kinetics process of a reacting $\mathrm{n}$-dodecane spray flame under compression ignition combustion condition. Energy Fuels 2019, 33, 11899-11912.

(22) Engine Combustion Network; https://ecn.sandia.gov/.

(23) Senecal, P. K.; Pomraning, E.; Richards, K. J.; Som, S. An investigation of grid convergence for spray simulations using an LES turbulence model. In SAE Technical Paper; SAE International: 2013 2013-01-1083.

(24) Ricart, L. M.; Reltz, R. D.; Dec, J. E. Comparisons of diesel spray liquid penetration and vapor fuel distributions with in-cylinder optical measurements. J. Eng. Gas Turbines Power 2000, 122, 588595.

(25) Schmidt, D. P.; Rutland, C. J. A new droplet collision algorithm. J. Comput. Phys. 2000, 164, 62-80.

(26) Frössling, N. Evaporation, heat transfer, and velocity distribution in two-dimensional and rotationally symmetrical laminar boundary-layer flow; Fysiografiska Saellskapets Handlingar: 1958, 168, AD-B189.

(27) Amsden, A. A. KIVA3V, Rel.2, Improvements to KIVA3V, LA Report; LA-UR-99-915, Los Alamos National Lab.: 1999.

(28) Senecal, P. K.; Pomraning, E.; Richards, K. J.; Briggs, T. E.; Choi, C. Y.; McDavid, R. M.; Patterson, M. A. Multi-dimensional modeling of direct-injection diesel spray liquid length and flame liftoff length using CFD and parallel detailed chemistry. SAE Trans. 2003, 1331. 2003-01-1043

(29) Luo, Z.; Som, S.; Sarathy, S. M.; Plomer, M.; Pitz, W. J.; Longman, D. E.; Lu, T. Development and validation of an n-dodecane skeletal mechanism for spray combustion applications. Combust. Theory Modell. 2014, 18, 187-203.

(30) Yao, T.; Pei, Y.; Zhong, B.-J.; Som, S.; Lu, T.; Luo, K. H. A compact skeletal mechanism for n-dodecane with optimized semiglobal low-temperature chemistry for diesel engine simulations. Fuel 2017, 191, 339-349.

(31) Cai, L.; Kroger, L.; Pitsch, H. Reduced and optimized mechanism for $\mathrm{n}$-dodecane oxidation. In 15 th International Conference on Numerical Combustion; 2015.

(32) Ren, S.; Kokjohn, S. L.; Wang, Z.; Liu, H.; Wang, B.; Wang, J. A multi-component wide distillation fuel (covering gasoline, jet fuel and diesel fuel) mechanism for combustion and PAH prediction. Fuel 2017, 208, 447-468.

(33) Westbrook, C. K.; Pitz, W. J.; Herbinet, O.; Curran, H. J.; Silke, E. J. A comprehensive detailed chemical kinetic reaction mechanism for combustion of n-alkane hydrocarbons from n-octane to $\mathrm{n}$ hexadecane. Combust. Flame 2009, 156, 181-199.

(34) Hiroyasu, H.; Kadota, T.; Arai, M. Development and use of a spray combustion modeling to predict diesel engine efficiency and pollutant emissions: Part I: Combustion modeling. Bull. JSME 1983, 26, 569-575.

(35) Nagle, J. Oxidation of carbon between $1000-2000^{\circ} \mathrm{C}$. In Proceedings of the Fifth Conference on Carbon; Pergamon: 1962, 154164.

(36) Wang, H.; Deneys Reitz, R.; Yao, M.; Yang, B.; Jiao, Q.; Qiu, L. Development of an n-heptane-n-butanol-PAH mechanism and its application for combustion and soot prediction. Combust. Flame 2013, $160,504-519$.

(37) Senecal, P. K.; Pomraning, E.; Richards, K. J.; Som, S. Gridconvergent spray models for internal combustion engine computational fluid dynamics simulations. J. Energy Resour. Technol. 2014, 136, No. 012204 .

(38) Tang, Q.; Liu, X.; Liu, H.; Wang, H.; Yao, M. Investigation on the dual-fuel active-thermal atmosphere combustion strategy based on optical diagnostics and numerical simulations. Fuel 2020, 276, 118023.

(39) Kee, R. J.; Rupley, F. M.; Miller, J. A. CHEMKIN II: A fortran chemical kinetics package for the analysis of gas-phase chemical kinetics; Sandia Laboratories Report, S. 89-8009B, Sandia National Laboratories: 1989.

(40) Bekdemir, C.; Somers, L. M. T.; de Goey, L. P. H.; Tillou, J.; Angelberger, C. Predicting diesel combustion characteristics with Large-Eddy Simulations including tabulated chemical kinetics. Proc. Combust. Inst. 2013, 34, 3067-3074.

(41) Siebers, D.; Higgins, B. Flame lift-off on direct-injection diesel sprays under quiescent conditions. SAE Trans. 2001, 400. 2001-010530

(42) Dec, J. E. Advanced compression-ignition engines-understanding the in-cylinder processes. Proc. Combust. Inst. 2009, 32, $2727-2742$

(43) Liu, X.; Wang, H.; Yao, M. Investigation of the chemical kinetics process of diesel combustion in a compression ignition engine using the large eddy simulation approach. Fuel 2020, 270, 117544. 